Check for updates

\title{
Post-operative Weight Gain After Total Knee Arthroplasty: Prevalence and Its Possible Attenuation Using Intraoperative Sensors
}

\author{
Gregory J. Golladay MDs; Gerald J. Jerry MDt; Kenneth A. Gustke MD;; Martin W. Roche $M D^{\beta}$; \\ Leah Elson BSc ${ }^{\jmath}$; Christopher Anderson MSc ${ }^{\partial}$
}

\begin{abstract}
As the proportion of adults with obesity continues to climb, so too does the need for total knee arthroplasty. Unfortunately, total knee replacement patients often experience post-operative weight gain, despite improved joint function. The purposes of this study were: 1) To execute a literature meta-analysis in order quantify the changes in body mass that are typically observed following TKA, and 2) Evaluate data from a prospective, multicenter study to assess any trends towards weight loss in a group of "balanced", sensor-assisted TKA patients. The literature review found that average proportion of patients who had weight gain after TKA is $47 \%$ to $66 \%$. In literature, the average post-operative weight gain was 9.5 lbs. $\left(1.6 \mathrm{~kg} / \mathrm{m}^{2} \mathrm{BMI}\right.$ increase), up to $14 \mathrm{lbs} .\left(2.3 \mathrm{~kg} / \mathrm{m}^{2}\right)$. In the multicenter study, only $30.4 \%$ of patients and $36.9 \%$ of patients exhibited weight gain at 6 months and 1 year, respectively. At the 1-year interval, this indicates an $11 \%$ decrease from reported averages ( $\mathrm{p}=0.049)$, up to $29 \%$ as reported by the NIH $(\mathrm{p}<0.001)$. The average weight gain in the multicenter patient group was $4.3 \mathrm{lbs}$. $\left(0.72 \mathrm{~kg} / \mathrm{m}^{2} \mathrm{BMI}\right.$ increase) at 6 months, and $3.5 \mathrm{lbs} .\left(0.58 \mathrm{~kg} / \mathrm{m}^{2}\right)$ at 1 year, both of which are non-clinically meaningful. The average weight loss of those in the non-gaining group was $7.8 \mathrm{lbs} .\left(1.3 \mathrm{~kg} / \mathrm{m}^{2}\right)$ at 6 months and $9.6 \mathrm{lbs}$. $\left(1.6 \mathrm{~kg} / \mathrm{m}^{2}\right)$ at 1 year. Both of these values are clinically meaningful. This evaluation demonstrates that weight gain after TKA is prevalent, but ensuring soft-tissue balance (via technologies such as intraoperative sensing) may help mitigate this expected increase in body mass.
\end{abstract}

Keywords: total knee arthroplasty, increased BMI, intraoperative sensors, weight gain, obesity

$\S$ VCU Medical Center, Department of Orthopaedic Surgery Richmond, VA

$\dagger$ Bone \& Joint Institute

Port Huron, MI

$¥$ Florida Orthopaedic Institute

Tampa, FL

B Holy Cross Hospital, Department of Orthopedic Surgery

Fort Lauderdale, FL

a Department of Clinical and Bioengineering Research

Orthosensor Inc., Dania, FL

Copyright 2014, Gregory J. Golladay, Gerald J. Jerry, Kenneth A. Gustke, Martin W. Roche, Leah Elson, Christopher Anderson. All rights reserved.

JISRF gives permission for reproduction of articles as long as notification and recognition is provided.

\section{Introduction}

The obesity epidemic has gone unchecked since its inception in the early 1980s. [3] As a result, over 35\% of adults in the United States are now classified as "obese" by the standards set forth by the Centers for Disease Control and Prevention. [4] This rapid increase in the BMI of Americans also results in a costly increase in medical spending. Per capita, the obese patient incurs an additional $\$ 1,429$ in annual health care expenditures beyond the medical costs of a patient with a normal BMI. [5] Nationally, 
these additional costs culminate in a 147 billion dollar financial burden every year. [5]

An elevated BMI is implicated in atherosclerosis, hypertension, cardiovascular disease, acute pancreatitis, ovarian and colon cancers, and steatohepatitis. [1,9] The musculoskeletal system is also adversely affected by obesity. Increased and asymmetric loading across bearing surfaces, in heavy patients, contributes to acceleration of lower limb osteoarthritis (Figure 1). As such, an unprecedented influx of younger patients are undergoing total knee arthroplasty (TKA), partly as a result of joint damage sustained from excess body mass. $[2,6]$

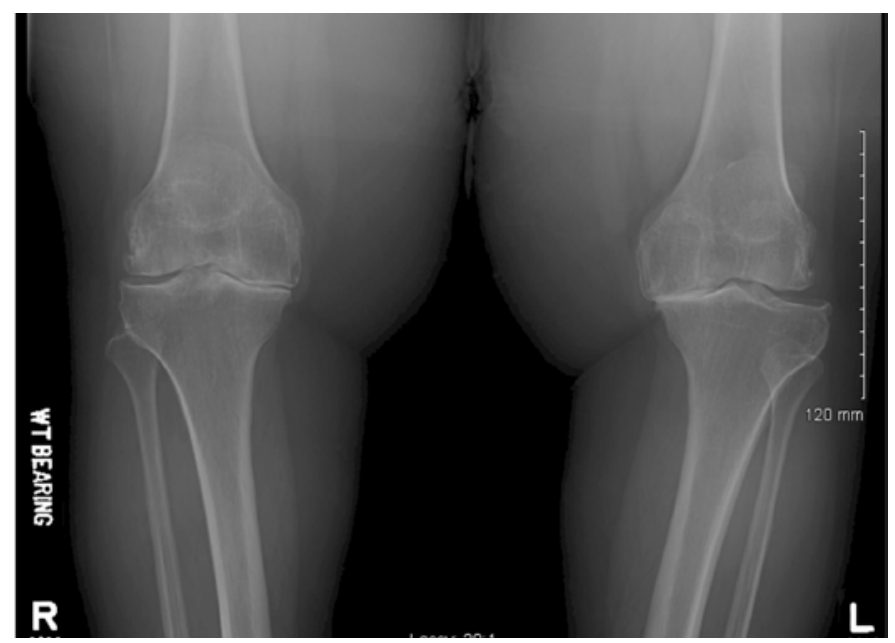

Figure 1. From the multicentric study, a 59-year old osteoarthritic patient with a BMI of $40 \mathrm{~kg} / \mathrm{m} 2$

Although many patients with advanced osteoarthritis report that reduced activity as a result of joint pain and dysfunction is responsible for their obesity, the majority of TKA patients have been shown to gain weight postoperatively, despite the restoration of joint function. [1014] Unfortunately, these arthroplasty procedures intended to facilitate a return to an active lifestyle have done little to reduce the prevalence of adulthood obesity, contrary to what might be expected. With no foreseeable reduction in the national obesity rate anticipated, it has become important to explore options that may mitigate weight gain and its associated risk factors. [7]

New technology, incorporating intraoperative sensing into knee replacement trials, has been developed to quantify intercompartmental balance in TKA. A recent publication showed that TKA patients with quantifiably balanced soft-tissue (intercompartmental load difference $\leq 15 \mathrm{lbs}$ ) had significantly higher activity levels, Knee Society and WOMAC scores at 6 months than patients with unbalanced soft-tissue. [15] We hypothesized that this increase in activity level and function would result in decreased incidence of weight gain, or even weight loss, when compared to historical controls. The purpose of this study was to evaluate changes in the body mass of patients with a quantifiably balanced TKA at 6 and 12 months, compared to an analysis of literature reporting weight change after primary TKA.

\section{Patients and Methods}

In order to quantify any changes in body mass that are typically observed after TKA, a blinded literature search and meta-analysis was performed by two contributing authors. Using PubMed, combinations of the following keywords were queried: "weight gain", "weight increase", "weight decrease", "TKA", "BMI increase", "obesity", "change in obesity", "change in BMI", "total knee arthroplasty", "total knee replacement," and "post-operative BMI".

Studies selected for inclusion in this analysis met the following criteria: all patients in the study had primary TKA; BMI data was collected pre-operatively and, at least, within 1-year of the surgical date; and the proportion of patients who gained or lost weight post-operatively was statistically described. All aforementioned criteria must have been met, and agreed upon by two participating authors, before subsequent inclusion in the data analysis.

In order to evaluate any trends toward weight loss, an analysis of 138 patients who had undergone sensor-assisted primary TKA was conducted. These patients were included as part of a U.S.-based, prospective, multicenter evaluation on soft-tissue balance using intraoperative sensors (Orthosensor Inc., Dania Beach, FL). The reason for reporting on this particular group of patients is due to its previously published findings, demonstrating statistically higher post-operative activity levels. [15] All patients in this analysis exhibited, as verified by the intraoperative sensors, soft-tissue balance (medial-lateral loading difference $\leq 15 \mathrm{lbs}$.) [15]

Pre- and post-operative (6-month and 1-year) BMI data was collected and evaluated. The resultant change in BMI (if any) was grouped into one of the following categories: "Group A" (weight loss/static weight), and "Group B" (weight gain).

All statistical evaluations were performed using SPSS - Version 21 (SPSS Inc., Chicago, IL). For the meta-analysis, Levene's homogeneity tests and $\mathrm{I}^{2}$ index analyses were executed. For the prospective portion, analysis of variance (ANOVA) was used to assess any statistical significance between the proportion of patients in Groups A, and B. For the purposes of this evaluation significance was defined as a $\mathrm{p}$-value $<0.05$, and heterogeneity was defined as a p-value $<0.1$. 


\section{Results}

\section{POST-TKA WEIGHT CHANGE IN LITERATURE}

The blinded literature search yielded a total of 82 results. Of those, 5 publications met all inclusion criteria required for the meta-analysis. [10-14] In total, 1,740 patients were included.

The average proportion of patients with reported weight gain following TKA was $47 \%$, with a maximum of $66 \%$, at their respective one-year intervals. The test for homogeneity of weight gain prevalence between all 5 publications yielded a Levene's statistic of 9.002 with a p-value $<0.001$. The $\mathrm{I}^{2}$ index was $94 \%$.

The publications by Zeni, et al., Riddle, et al., Abu-Rejab, et al., and Heisel, et al. reported the average weight gain of their patient cohorts as 14 lbs., 11 lbs., $10 \mathrm{lbs}$., and 3 lbs., respectively. Odds ratios reported by the Riddle, et al. group indicated that patients with total knee arthroplasty are 1.6 times more likely to experience a "clinically important" weight gain ( $\geq 5 \%$ of their baseline body weight), when compared with a non-TKA control group. [12]

\section{SENSOR-ASSISTED TKA PATIENTS EXHIBITING WEIGHT LOSS}

Of the patients enrolled in the multicenter evaluation, 138 had 6-month BMI data; 87 had 1-year BMI data.

At 6 months, 30.4\% gained weight; at 1 year, 36.9\% gained weight. Thus, at 6-months Groups A and B represented $69.6 \%$ and $30.4 \%$, respectively; at 1-year Groups A and $\mathrm{B}$ represented $63.1 \%$ and $36.9 \%$, respectively.

An ANOVA analysis of the two time intervals showed that the proportion of patients that did not gain weight (Group A) was significantly higher than those that gained weight (Group B) (p $<0.001$ at 6 -months; $p<0.001$ at 1-year). The average weight gain at 6 months was 4.3 lbs. $\left(0.72 \mathrm{~kg} / \mathrm{m}^{2} \mathrm{BMI}\right)$; the average weight gain at 1 year was $3.5 \mathrm{lbs}$. $\left(0.58 \mathrm{~kg} / \mathrm{m}^{2} \mathrm{BMI}\right)$. The average weight loss at 6-months was $7.8 \mathrm{lbs}$. $\left(1.3 \mathrm{~kg} / \mathrm{m}^{2} \mathrm{BMI}\right)$, and the average weight loss at 1-year was $9.6 \mathrm{lbs}$. (1.6 kg/m² BMI) (Figure 2).

Of those patients who underwent surgery, classified as "morbidly obese" (BMI>35), 25.3\% dropped to a lower BMI classification by the 1-year follow-up interval. Of those patients who began surgery, classified as "obese" $(30<\mathrm{BMI}<35), 15.1 \%$ dropped to a lower BMI classification by the 6 -month interval.

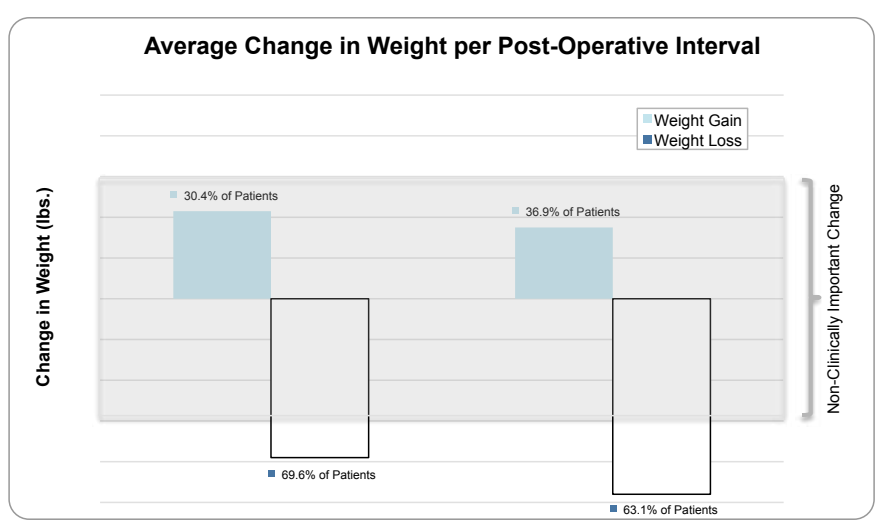

Figure 2.

\section{Discussion}

In the United States, the rate of obesity among adults has reached epidemic proportions. [3,4] Statistical projections predict that this increasing rate of obesity will continue through 2030. [7] Thus, it will be necessary for the orthopaedic surgeon to contend with the risks and complications associated with performing total knee arthroplasty on a younger, heavier population. However, it has been reported in literature that knee replacement patients commonly gain weight in the first year after surgery.

In this evaluation, a meta-analysis of literature was performed to quantify the post-operative change in body mass typically observed after TKA. Amongst the 5 publications that met all criteria for the analysis (1,740 patients), the Levene's statistic showed 9.002, with a p-value $<0.001$. This indicates that there is a high level of heterogeneity in the literature that is currently available. The $\mathrm{I}^{2}$ index specifies the heterogeneity with a $94 \%$ variance value. These numbers, together, indicate that power is lacking to make direct statistical comparisons; they explicate the need for an increase in similar studies to be published.

Even so, descriptive comparisons among the literature can still be made, and they are staggering. The average proportion of patients that exhibit post-operative weight gain, at a one-year interval, was $47 \%$. This value was reported to be as high as $66 \%$ in a study sanctioned by the National Institute of Health. [11] Four of the five publications also specified the post-operative weight gain. The average reported was an increase of $9.5 \mathrm{lbs}$., which corresponds to a $1.6 \mathrm{~kg} / \mathrm{m}^{2}$ increase in BMI. This value was as high as 14 lbs., or a $2.3 \mathrm{~kg} / \mathrm{m}^{2}$ increase in BMI. [11] When odds ratios were calculated, it was found that patients receiving TKA are 1.6 times more likely to exhibit "clinically important" weight gain ( $\geq 5 \%$ of their baseline body weight) than a control group. [12] Thus, weight gain and BMI increase after TKA is something that is calculable, predictable, and prevalent. 
Yet, the evidence from this prospective multicentrer study indicates that this does not necessarily need to be the case. For this evaluation, a group of sensor-assisted TKA patients - previously reported in literature to have exhibited statistically higher activity levels [15] — were evaluated for post-operative BMI changes at 6 months and 1 year. It was found that the majority of multicenter patients showed a trend towards no net weight gain (69.6\% at 6 months; $63.1 \%$ at 1 year). As such, only $30.4 \%$ and $36.9 \%$ of patients gained weight at 6 months and 1 year, respectively. On average, at 1 year, this is an 11\% decrease from what is reported in literature $(\mathrm{p}=0.049)$. When compared with data from the National Institute of health, this is a $29 \%$ decrease $(\mathrm{p}<0.001)$. [11]

Among patients who did gain weight after balanced TKA, the average weight gain at 6 months was only 4.3 lbs.; the average weight gain at 1 year was $3.5 \mathrm{lbs}$., neither of which were clinically meaningful. [8]

Most importantly, the average weight loss in this cohort, at 6-months, was $7.8 \mathrm{lbs} .\left(1.3 \mathrm{~kg} / \mathrm{m}^{2}\right)$, and the average weight loss at 1 -year was $9.6 \mathrm{lbs} .\left(1.6 \mathrm{~kg} / \mathrm{m}^{2}\right)$. This decrease in BMI, at both time points, represents a clinically relevant interval for weight loss $\left(\Delta \mathrm{BMI}>1 \mathrm{~kg} / \mathrm{m}^{2}\right)[8]$, and is most likely attributed to the increased activity levels of these patients, previously reported. [15]

What has made this group of patients so distinct is their verifiably-balanced soft-tissue envelopes. Published in the initial report, were the results of a multivariate logistic regression analysis which demonstrated that the most significant contributing variable to the observed increase in activity level and outcomes scores, was whether or not the medial-lateral loading on the bearing surface was "balanced" in the coronal plane. This balance was quantified using intraoperative sensors, and must have necessarily registered as a mediolateral loading difference $\leq 15 \mathrm{lbs}$. through the passive range of motion. All patients included in this analysis of change in weight and BMI were of the same "balanced" cohort previously published. [15]

There were weaknesses in this study. First, the number of publications which focus on post-operative weight gain after TKA is limited. While we can make descriptive comparisons between the publications used in our analysis, it would take more than the 5 that met inclusion criteria for the meta-analysis to provide statistically meaningful conclusions. However, the main argument is still clear: weight gain amongst TKA recipients occurs commonly and predictably. Second, not all of the centers in our multicenter evaluation were collecting post-operative BMI. While the numbers we were able to collect are strong, it is always preferable to collect as much data as possible for an analysis of this type. Third, we do not know how the balanced cohort of patients is performing kinematically. With a gait analysis, it may be better understood why these balanced patients are exhibiting higher activity levels and, consequently, losing weight when compared with non-sensorassisted TKA patients.

In a society in which obesity levels continue to climb, every measure should be undertaken to mitigate risks for potential weight gain. Historically, total knee arthroplasty has not resulted in weight loss. In this study, patients with a quantifiably balanced TKA were less likely to gain weight and more likely to lose weight at 6 and 12 months versus those reported in the meta-analysis; those that gained weight did so in small increments that were not clinically meaningful. Sensor-balanced TKA results in higher activity levels that may be responsible for this improvement in postoperative weight and body mass change. Quantitative knee balancing using intraoperative sensing technology holds promise for improved outcomes. Longer-term follow-up and additional study of the kinematics of sensorbalanced TKA is warranted to understand the impact that this technology can have on patient outcomes.

\section{References}

1. National Institutes of Health. Clinical guidelines on the identification, evaluation, and Treatment of overweight and obesity in adults - The evidence report. Obes Res 6(Suppl 2):51S-209S. 1998.

2. National Institute for Health and Clinical Excellence. National Collaborating Centre for Chronic Conditions Osteoarthritis: national clinical guideline for care and management in adults. London, UK: NICE; 2008.

3. McLellan F. Obesity rising to alarming levels around the world. Lancet.2002 Apr 20;359(9315):1412.

4. Ogden CL, Carroll MD, Kit BK, et al. Prevalence of Obesity in the United States, 2009-2010. NCHS Data Brief U.S. Dept Health and Hum Serv. 2012; (42): $1-7$

5. Finkelstein EA, Trogdon JG, Cohen JW, et al. Annual Medical Spending Attributable To Obesity: Payer-And Service-Specific Estimates. Health Affairs. 2009;28(5):822-831

6. Nicholls AS, Kiran A, Javaid MK, et al. Change in body mass index during middle age affects risk of total knee arthoplasty due to osteoarthritis: a 19-year prospective study of 1003 women. Knee. 2012 Aug;19(4):316-319.

7. Kelly T, Yang W, Chen CS, et al. Global burden of obesity in 2005 and projections to 2030. International Journal of Obesity (2008) 32, 1431-1437

8. Institute of Medicine, National Academy of Sciences. Weighing the Options: Criteria for Evaluating Weight Management Programs. Government Printing Office: Washington, DC, 1995.

9. P. Kopelman. Health risks associated with overweight and obesity. Obesity Reviews. 2007; 8(1):13-17.

10. Donovan J, Dingwall I, McChesney S. Weight change 1 year following total knee or hip arthroplasty. ANZ J Surg. 2006; 76(4): 222-225.

11. Zeni JA, Snyder-Mackler L. Most patients gain weight in the 2 years after total knee arthroplasty: comparison to a healthy control group. (NIH Public Access Manuscript) Osteoarthritis Cartilage. 2010; 18(4): 510-514.

12. Riddle DL, Singh JA, Harmsen WS, et al. Clinically important body weight gain following knee arthroplasty: a five-year comparative cohort study. Arthritis Care Res (Hoboken). 2013; 65(5): 669-677.

13. Abu-Rajab RB, Findlay H, Young D, et al. Weight changes following lower limb arthroplasty: a prospective observational study. Scott Med J. 2009; 54(1): 26-28.

14. Heisel C, Silva M, dela Rosa MA, et al. The effects of lower-extremity total joint replacenet for arthritis on obesity. Orthopedics. 2005; 28(2): 157-159.

15. Gustke KA, Golloday GJ, Roche MW, et al. A new method for defining balance: promising short-term clinical outcomes of sensor-guided TKA. J Arthroplasty. 2013; doi:pii: S0883-5403(13)00802-4.10.1016/j.arth.2013.10.020 [E-pub ahead of print]. 